\title{
BMJ Global Health Community engagement for successful COVID-19 pandemic response: 10 lessons from Ebola outbreak responses in Africa
}

Julienne Ngoundoung Anoko, ${ }^{1}$ Boureima Rodrigue Barry, ${ }^{1}$ Hamadou Boiro, ${ }^{2}$ Boubacar Diallo, ${ }^{3}$ Amadou Bailo Diallo, ${ }^{1}$ Marie Roseline Belizaire, ${ }^{4}$ Morry Keita, ${ }^{1}$ Mamadou Harouna Djingarey, ${ }^{5}$ Michel Yao N'da, ${ }^{3}$ Zabulon Yoti, ${ }^{3}$ Ibrahima-Soce Fall, ${ }^{6}$ Ambrose Talisuna (i) ${ }^{3}$

To cite: Anoko JN, Barry BR, Boiro $\mathrm{H}$, et al. Community engagement for successful COVID-19 pandemic response: 10 lessons from Ebola outbreak responses in Africa. BMJ Global Health 2020;4:e003121. doi:10.1136/ bmjgh-2020-003121

Handling editor Seye Abimbola

Received 10 June 2020

Revised 18 July 2020

Accepted 21 July 2020
Check for updates

(c) Author(s) (or their employer(s)) 2020. Re-use permitted under CC BY-NC. No commercial re-use. See rights and permissions. Published by BMJ.

For numbered affiliations see end of article.

Correspondence to Dr Ambrose Talisuna; talisunaa@who.int

\section{INTRODUCTION}

During public health emergencies, such as the current COVID-19 Public Health Emergency of International Concern, communities are often poorly involved in the planning and implementation of interventions, yet their commitment is fundamental to control outbreaks.

African countries are responding to the COVID-19 pandemic with restrictive public health measures such as states of emergency and either total or partial lockdowns. All the countries share similar structural challenges and vulnerabilities, including and not limited to weak health systems, an informal economy, with more than half the population 'making do' or 'getting by day by day' and living from hand to mouth. These vulnerabilities challenge the acceptance and compliance of the package of restrictive health measures.

The structural weakness of health systems in Africa means that few critically ill patients will have access to medical care in intensive care units and the kind of medical technology available in these facilities. Preventing spread of infection is essential. As a result, reduced social interactions and increased physical distancing are a central part of many public health strategies and this requires co-constructing of solutions that are acceptable and feasible, and that foster commitment of affected communities.

Lessons learnt from Ebola outbreak response in West Africa and most recently in the Democratic Republic of Congo have demonstrated that the co-construction of sociocultural solutions has fostered commitment of affected communities and has
Summary box

Communities are often poorly involved in the planning and implementation of interventions, yet their commitment is fundamental to control outbreaks in all the phases.

- African countries are responding to the COVID-19 pandemic with measures such as restrictions of movement of people, home confinements and states of emergency such as total or partial lockdowns.

- But structural challenges and vulnerabilities of health systems and the well-being of people challenge the acceptance and compliance with this package of measures.

- Lessons learnt from responding to Ebola outbreaks in Africa (2014-2016 and 2018-2020) can strengthen community engagement to enhance the community ownership of the COVID-19 pandemic response.

- We present 10 lessons learnt from responding to Ebola that African countries should quickly adapt in their response to the COVID-19 pandemic, namely:

1. involve social scientists early in the response;

2. mobilise family leaders for surveillance, case detection, contact identification and follow-up and quarantine;

3. treat contacts with dignity and the empathy they deserve;

4. communicate laboratory results promptly;

5. care for the severely ill, while maintaining family connections;

6. prevent stigmatisation of people and the families of those who recover;

7. recruit local staff in the response and involve local people to build response structures;

8. mobilise and involve resistant communities in the response to overcome dissent;

9. involve grass-roots leaders in the preparation and implementation of response measures;

10. mobilise media players, including social media networks. 


\section{Summary box}

- Health actors, community leaders and communities must coconstruct options for COVID-19 response that are acceptable, and feasible, and foster commitment of affected communities.

- This approach calls for an urgent paradigm shift from a predominantly biomedical approach to outbreak response to one that balances biomedical and social science approaches.

succeeded in enhancing community engagement and ownership of the response.

Community engagement and co-construction are two complementary notions: the first being the end of a process, and the second being the method or steps to achieve a desired goal. Experiences of community engagement and co-construction during Ebola response have shown that when communities were involved in problem analysis and co-construction of solutions, they took ownership of the response interventions and committed to efforts to curb the epidemic.

We summarise here, under 10 successful lessons learnt from Ebola, responses that can strengthen community engagement in the fight against the COVID-19 pandemic, and specifically with respect to compliance with state of emergency measures, including partial or total lockdowns.

\section{LESSON 1: INVOLVE SOCIAL SCIENTISTS EARLY IN THE RESPONSE}

During emergency response, social science experts bring specific expertise in analysing the dynamics of actors and communities engaged in the response in their social, cultural, historical, political and economic contexts. ${ }^{1}$ In this way, social scientists can build bridges or facilitate dialogue in challenging situations. Further, social scientists can facilitate the co-construction of culturally and epidemiologically appropriate solutions and redefine interventions for increased community ownership. In this way, response measures can account more fully for the human experience, and reduce potential for unintended additional suffering to communities, some of which may be destabilised by fear of disease, death and conflict prevention.

There is often a misconception about the homogeneity of communities. Community engagement starts from the premise that community groups are heterogeneous and that the diversity of opinions and sociocultural perspectives must account for acceptable solutions to be developed. Epidemics often reawaken old resentments and conflicts within and between communities. These conflicts can negatively affect the success of public health interventions and hamper their ownership by communities. To find mutually acceptable solutions, responders must account for the unique and varied perspectives of affected communities and be open to finding unarticulated and, at times, unexpected solutions.
LESSON 2: MOBILISE FAMILY LEADERS FOR SURVEILLANCE, EARLY CASE DETECTION, CONTACT IDENTIFICATION AND FOLLOW-UP, AND QUARANTINE

Early case detection, contact tracing, as well as contact quarantine require the commitment of families and community leaders; these interventions can themselves be 'violent and destabilizing' and reminiscent of police house arrest. Involving the head of the family, for example, who is the provider and responsible for protecting the family, ensures a quality interlocutor who has the power to mobilise family members. During Ebola, even in situations of extreme reluctance to follow-up contacts, it was useful to mobilise a family leader to take on this task with his family. By using his duty to protect, he was able to follow-up his family's contacts properly and with the trust of the surveillance teams.

\section{LESSON 3: TREAT CONTACT PERSONS WITH DIGNITY AND THE EMPATHY THEY DESERVE}

Contacts must be treated with dignity and not as 'contaminating subjects'. Regardless of their place in the social hierarchy, their change of status due to suspicion of disease puts their status or place in the family and/or community at risk. It is important to set up a mechanism to facilitate communication between the contacts in quarantine and their family, as well as access to quality psychosocial care provided by experts who speak their language. Quarantine facilities should be pleasant, ventilated and with play areas to account for small children, if possible. Moreover, it is important to ensure that meals for people in quarantine are better than those provided by their families, thus alleviating the traumatic experience of quarantine. Experience from previous epidemics highlights how attending to theses aspects is critical to prevent escapes and promote acceptance of quarantine. If resources permit, it is advisable to provide some additional 'treats' such as drinks, chocolates, cookies and balloons for the children of those in quarantine

\section{LESSON 4: COMMUNICATE LABORATORY RESULTS PROMPTLY TO THE PATIENT}

The diagnosis of COVID-19, like that of Ebola, requires confirmation by a biological test-RT-PCR (a method of molecular biology) - which takes at least 4 hours to complete. Added to this is the time needed to transmit the results to experts, the authorities and finally to the patient. As a result, patients may only know the result of the test after 24 hours in urban areas and sometimes longer in rural areas. For the patient and family this waiting period is filled with uncertainty, causing disruption and anxiety. It is strongly recommended to establish a rapid process for communicating the results to doctors in the field to relieve the anxiety of the patients and their families and to initiate the protective public health actions very quickly. 
LESSON 5: CARE FOR THE SEVERELY ILL AND MAINTAIN FAMILY CONNECTIONS

COVID-19 gives rise to a spectrum of illness with around $80 \%$ of patients experiencing mild to moderate illness. Those who become severely ill and who have access may receive hospital care. Hospitalisation of patients means transferring them from a familiar environment to a stressful environment; medical and paramedical personnel who provide care are strangers and wear personal protective equipment, such as goggles and surgical masks, and this can reinforce disorientation, anxiety and fear. There are multiple uncertainties facing both patients and their families, not least of which involves uncertainty regarding the progression of disease. Patients and their families need proactive, clear information about the hospital setting and what to expect. The way in which the physical environment is structured communicates a lot to patients and families. Ensuring a toilet is easily available, having dedicated waiting rooms with provision for young children and paying attention to privacy needs are small but important aspects. At an interpersonal level, patient-centred communication can help reduce anxiety and isolation. Getting updates from the patient beyond their clinical condition, encouraging them to get well, smiling behind the protective mask and speaking in the patient's language all contribute to providing reassurance and quality humane care for the hospitalised person. It is also helpful to keep the patient connected with relatives by allowing phone calls and safe visits of a selected family member where feasible.

\section{LESSON 6: PREVENT STIGMATISATION OF PEOPLE WHO RECOVER AND THEIR FAMILIES}

Fear of the disease often leads to stigmatisation and 'scapegoating' of patients and their families. Preventing stigma and acting to counter it helps reduce the negative effects of the epidemic on social cohesion. The mobilisation of psychologists at the beginning of the epidemic is an effective means of mitigation. The involvement of local authorities and leaders helps protect and support victims of stigma and reassure the community. In addition, there are endogenous reintegration mechanisms that are important to explore; these mechanisms are very useful outside crises to resolve community disputes, and restore peace and forgiveness. People who have recovered from COVID-19 also need the acceptance of their communities to prevent stigma.

\section{LESSON 7: RECRUIT LOCAL STAFF IN THE RESPONSE, INCLUDING LOCAL PEOPLE TO BUILD THE STRUCTURES OF THE RESPONSE}

The management of a response is very resource intensive. For a population and especially for young people who are facing unemployment and whose socioeconomic demands are not always met, the response can be an opportunity to find jobs and relieve their suffering. During Ebola outbreak response, partners often recruit young people and women into the response services; for example, youth and women employed in the neighbourhoods where response structures (treatment units, points of control/points of entry) have been built. This has helped facilitate community acceptance of these new structures, preventing reluctance, vandalism and violence against the health teams.

\section{LESSON 8: MOBILISE THE MOST RESISTANT PEOPLE IN THE RESPONSE TO OVERCOME DISSENT}

Fear and frustration can provoke popular uprisings. However, as in any social movement, there are leaders who direct the hostilities. During Ebola, many uprisings, reticence and resistance were defused by recruiting these leaders into the response. They were thus able to control their own groups, ensure the security of teams and facilitate access to communities for public health activities. Young people can be involved in monitoring and securing their areas of residence. This would prevent risk taking, recklessness and vandalism.

\section{LESSON 9: INVOLVE GRASS-ROOTS LEADERS IN THE PREPARATION AND IMPLEMENTATION OF RESPONSE MEASURES, INCLUDING CONTAINMENT AND EMERGENCY PREPAREDNESS}

It is essential to be able to discuss the conditions and operationalisation of restrictive measures with community leaders, so that solutions can be co-constructed with the communities. Involving religious leaders may strengthen the spiritual tranquillity and to some extent, the predisposition to fight the disease as a spiritual battle. This tranquillity is very often sought among the supporters of socioreligious institutions, in localities considered sacred, depositories of mystical powers that can change the course of events, based on prayers and ritual sacrifices. Failing this, health measures such as a state of emergency and lockdowns can be considered to be in the sole interest of the authorities and political leaders. Some credible and influential community leaders are also very useful in managing rumours, misinformation and accountability in the face of unfulfilled promises by certain actors that can undermine community engagement.

\section{LESSON 10: MOBILISE MEDIA PLAYERS AND TAKE SOCIAL NETWORKS INTO ACCOUNT}

African populations in general remain closely linked to the traditional media (radio and television to a lesser extent). Treating media actors as partners in tackling pandemic challenges allows response actors to properly engage them with messages disseminated through their channels and appreciated by the communities. Involving the media as partners also provides access to their own social networks, because most people involved in the media are also heavy users of social networks. Finally, associating media actors and considering social networks enables the activation of the media communication 
monitoring function, which remains a challenge during public health emergencies.

\section{CONCLUSION}

Given the experience of responding to Ebola epidemics in Africa, it is imperative that communities must be accountable to the response to COVID-19. Health actors and authorities must co-construct solutions to address COVID-19 with community leaders and communities. However, a 'one size fits all' approach to community engagement is likely to fail. Each community is unique, and engagement must be contextualised to affected communities of each country. This engagement of cooperation with communities calls for an urgent change in the approach to health emergency response. All member states, health authorities and humanitarian actors are urgently called on to quickly move from a dominant biomedical design of public health emergency response to a public health design that balances biomedical paradigms with those of social sciences.

\section{Author affiliations}

${ }^{1}$ World Health Organisation, Emergency Preparedness and Response Programme, Dakar Hub, Senegal

${ }^{2}$ National Institute for Studies and Research, Bissau, Guinea-Bissau and Faculty of Sociology, Anthropology and Folkloristics, University of Iceland, Reykjavik, Iceland ${ }^{3}$ World Health Organisation, Regional Office for Africa, Emergency Preparedness and Response Programme, Brazzaville, Congo

${ }^{4}$ World Health Organisation Country Office, Nouakchott, Mauritania

${ }^{5}$ World Health Organisation Country Office, Cotonou, Benin
${ }^{6}$ World Health Organisation, Health Emergency Programme, Geneva, Switzerland

Twitter Julienne Ngoundoung Anoko @AnokoJulienne and Marie Roseline Belizaire @MR_Belizaire

Acknowledgements Dr Nina Gobat and Ms Maria Caterina Ciampi for reviewing the manuscript.

Contributors JNA, BRB, ABD and BD complied the Ebola response lessons learnt. $A B D, M R B, M K$ and MHD reviewed the concept. JNA, MYN, ZY, ISF and AT reviewed the concept and tailored it to the COVID-19 response. JNA wrote the first draft and AT extensively reviewed the draft. All authors have reviewed and approved the final manuscript.

Funding The authors have not declared a specific grant for this research from any funding agency in the public, commercial or not-for-profit sectors.

Competing interests None declared.

Patient consent for publication Not required.

Provenance and peer review Not commissioned; internally peer reviewed.

Data availability statement № additional data are available.

Open access This is an open access article distributed in accordance with the Creative Commons Attribution Non Commercial (CC BY-NC 4.0) license, which permits others to distribute, remix, adapt, build upon this work non-commercially, and license their derivative works on different terms, provided the original work is properly cited, appropriate credit is given, any changes made indicated, and the use is non-commercial. See: http://creativecommons.org/licenses/by-nc/4.0/.

\section{ORCID iD}

Ambrose Talisuna http://orcid.org/0000-0001-6436-3415

\section{REFERENCE}

1 Abramowitz S. Ten Things that Anthropologists Can Do to Fight the West African Ebola Epidemic., 2014. Available: http://somatosphere. net/2014/ten-things-that-anthropologists-can-do-to-fight-the-westafrican-ebola-epidemic.html/ [Accessed Apr 2020]. 